\title{
Comprehensive treatment of dementia with Lewy bodies
}

Brendon $\mathrm{P}$ Boot $^{1,2}$

\begin{abstract}
Dementia with Lewy bodies is an under-recognized disease; it is responsible for up to $20 \%$ of all dementia cases. Accurate diagnosis is essential because the management of dementia with Lewy bodies is more complex than many neurodegenerative diseases. This is because alpha-synuclein, the pathological protein responsible for dementia with Lewy bodies (and Parkinson's disease), produces symptoms in multiple domains. By dividing the symptoms into cognitive, neuropsychiatric, movement, autonomic, and sleep categories, a comprehensive treatment strategy can be achieved. Management decisions are complex, since the treatment of one set of symptoms can cause complications in other symptom domains. Nevertheless, a comprehensive treatment program can greatly improve the patient's quality of life, but does not alter the progression of disease. Cholinesterase inhibitors are effective for cognitive and neuropsychiatric symptoms; rivastigmine has the widest evidence base. Special care needs to be taken to avoid potentially fatal idiopathic reactions to neuroleptic medications; these should be used for short periods only when absolutely necessary and when alternative treatments have failed. Pimavanserin, a selective serotonin 5-HT2A inverse agonist, holds promise as an alternative therapy for synuclein-associated psychosis. Levodopa/carbidopa treatment of parkinsonism is often limited by dopa-induced exacerbations of neuropsychiatric and cognitive symptoms. Autonomic symptoms are under-recognized complications of synucleinopathy. Constipation, urinary symptoms and postural hypotension respond to standard medications. Rapid eye movement sleep behavior disorder is highly specific (98 \%) to the synucleinopathies. Nonpharmacological treatments, melatonin and clonazepam are all effective.
\end{abstract}

\section{Introduction}

Dementia with Lewy bodies (DLB) is an under-recognized disease. The diagnostic criteria have low sensitivity (12 to $32 \%)$ and high specificity (>95\%) [1], so many cases are not diagnosed. Therefore, meta-analytic studies suggesting that DLB accounts for $4 \%$ of dementia diagnoses [2] underestimate the true prevalence [3], which may be closer to $20 \%$ of dementia [4, 5]. Parkinson's disease dementia (PDD) accounts for a further 3 to $5 \%$ of dementia cases $[5,6]$. Both DLB and PDD are due to the pathological accumulation of alpha-synuclein, but patients with parkinsonism for 1 year prior to cognitive decline are classified as PDD [4]. Cognitive decline and parkinsonism are insidious, so the distinction can be difficult to draw and may be influenced by the subspecialty interest of the diagnosing neurologist (for example, movement disorder versus behavioral neurology) [1, 7]. Data on the relative

\footnotetext{
Correspondence: bboot@partners.org

'Department of Neurology, Brigham and Women's Hospital, 221 Longwood Avenue, Boston, MA 02115, USA

${ }^{2}$ Harvard Medical School, 25 Shattuck Street, Boston, MA 02115, USA
}

frequency of DLB and PDD may be similarly affected by this subspecialty referral pattern. Whether or not the distinction has treatment implications is difficult to determine. This review highlights the distinction only where clinically relevant differences in outcomes have been noted. Restricting this review only to evidence-based treatments would mean that it could not be comprehensive, since many treatments have not been studied in DLB or PDD populations. In these instances, evidence from Parkinson's disease (PD) studies is used to guide clinical recommendations.

The management of DLB is replete with quandaries: in choosing to treat one symptom, we often produce complications in other facets of the disease. For example, dopamine replacement for motor symptoms frequently exacerbates a patient's neuropsychiatric symptoms, antipsychotic treatment of hallucinations risks a potentially fatal adverse reaction, and cholinesterase inhibitor treatment of cognitive symptoms can complicate cardiac and gastrointestinal dysautonomia. These quandaries make the treatment of DLB challenging, yet just as rewarding 
as navigating between Scylla and Charybdis. The sideeffect proclivity applies to medications prescribed by other physicians, so it is essential to rationalize treatment and to communicate with other care providers about the complexities of the disease. An understanding of the pervasive effects of alpha-synuclein can also assist the physician to make sense of nonspecific or vague complaints, particularly when advanced disease impairs a patient's ability to communicate. For example, a feeling of general malaise or lethargy can reflect orthostatic hypotension, a common and under-recognized feature of the disease.

Many symptoms of DLB are noncognitive in nature, and many are under-recognized [8-10]. It can be helpful to divide the array of symptoms into five symptom categories: cognitive, neuropsychiatric, movement, autonomic, and sleep. Patients often view DLB as a purely cognitive disease, and consequently will not volunteer noncognitive symptoms since they do not believe they are a consequence of the disease. Directed questions in each of the five categories can form the basis of a comprehensive treatment strategy that can improve the patient's quality of life [11]. The disease course can be rapid, although prognosis varies between individuals. In one study, life expectancy at diagnosis is 2.3 years shorter for DLB compared with Alzheimer's disease [10].

\section{Cognitive symptoms}

DLB-associated deficits in attention, executive function, and visuospatial ability respond well to cholinesterase inhibitor treatment [12-14]. In meta-analyses, the standardized mean treatment effects are 0.34 for cognition and 0.20 on behavioral and functional measures [13], although most of the source data are from PDD patients. These effects compare favorably with cholinesterase inhibitor treatment of Alzheimer's disease [15], because the targets of therapy are relatively preserved in DLB. Compared with Alzheimer's patients, DLB patients have relatively little neuronal loss but profound cholinergic dysfunction $[5,16]$. The characteristic fluctuations in cognition in DLB are difficult to manage; they may have multiple contributing causes [17]. Cholinesterase inhibitor treatment is associated with reduced mortality; mortality odds ratios in treatment trials are $0.28(P=0.03)$ despite increases in adverse events on therapy (odds ratio $1.64, P=0.0003)$ [14].

There are no head-to-head trials comparing efficacy of the cholinesterase inhibitors in DLB or PDD, but rivastigmine has the widest evidence base [12, 18, 19]. A Movement Disorder Society evidence-based review concluded that rivastigmine is effective in PDD, but that the data for other cholinesterase inhibitors and memantine are inconclusive [20]. Special care is needed when starting cholinesterase inhibitors in patients with DLB because of frequent disease-associated autonomic dysfunction [21].
Cardiac denervation [22] might increase the risk of symptomatic bradycardia [13, 23], or QT prolongation. Gastrointestinal dysautonomia [24, 25] means patients may be more at risk for the common cholinesterase inhibitor side effects of nausea, vomiting, diarrhea, anorexia, and weight loss $[13,26]$. To treat these, the clinician should eschew antagonists of dopamine, acetylcholine, or histamine in favor of 5HT-3 receptor antagonists such as ondansetron or granisetron. Rivastigmine has a transdermal formulation with fewer gastrointestinal side effects. DLB patients frequently have disordered sleep and so may be more likely to experience the vivid dreams that are an underrecognized side effect of cholinesterase inhibitors. These dreams can be limited by avoiding night-time doses; for cholinesterase inhibitors that require twice-daily dosing, the second dose may be given in the afternoon.

Only one of four trials of memantine in DLB/PD/PDD found significant effects in the primary outcome [27]. The results may be driven by data from PDD rather than DLB subjects, and may only be present with concurrent cholinesterase inhibitor treatment [27, 28]. Atomexetine [29], rasagiline [30] and levodopa [31, 32] have variable effects on cognition in PD/PDD populations [33].

\section{Neuropsychiatric symptoms \\ Anxiety and depression}

Anxiety and depression are common in DLB; they affect $27 \%$ and $59 \%$ of cases, respectively [10]. Like many nonmotor symptoms of synucleinopathy, anxiety and depression can predate the onset of parkinsonism and dementia by decades $[10,21,34]$, possibly due to early pathology in serotonergic projection cells of the dorsal raphe [35, 36]. Incipient synucleinopathy should therefore be considered in the differential diagnosis of late-onset anxiety and depression, particularly in patients without an obvious precipitant and/or subtle parkinsonism [37, 38].

There are no controlled trials of treatments for anxiety in DLB or PDD [33]. Depression was one of four neuropsychiatric symptoms in a composite measure that improved in trials of rivastigmine [39] and olanzapine [27, 40]. A single, uncontrolled trial of citalopram and risperidone in 31 patients found no improvement for either drug after 12 weeks [41]. Otherwise, there is a paucity of evidence in the treatment of depression in DLB. Serotonin and serotonin/norepinephrine reuptake inhibitor antidepressants have mixed results in the treatment of PD-related depression [20, 42, 43]. Electroconvulsive treatment and transcranial magnetic stimulation are both effective in DLB [44, 45].

\section{Hallucinations and delusions}

Hallucinations occur in 60 to $70 \%$ of DLB patients [8]. Commonly, they begin in the first 2 or 3 years of the disease whereas they are a late phenomenon in Alzheimer's 
disease [46]. There may also be qualitative differences. In Alzheimer's disease, hallucinations generally have a threatening or fearful quality [47]. They are often accompanied by delusions of suspicion [47]. In contrast, the hallucinations in DLB are often (but not always) nonthreatening misperceptions of ambiguous stimuli. For example, a patient may misinterpret a shadow to be a person or an animal. Tests of these misperceptions, termed pareidolias, accurately differentiate DLB from Alzheimer's disease [48]. Electing not to treat these symptoms is often appropriate, but cholinesterase inhibitor therapy is safe and effective [39]. In one study of PDD, more than $90 \%$ of patients reported reduced visual hallucinations with cholinesterase inhibitor use [12]. The hallucinations can be minimized by regular vision correction and a bright light or no light policy, whilst minimizing the risk of falls. Medications that can exacerbate neuropsychiatric symptoms in DLB should also be stopped. These include anticholinergic medications, amantadine, dopamine agonists, monoamine oxidase inhibitors, catechol-O-methyl transferase inhibitors, and levodopa, bearing in mind that abrupt cessation can trigger the neuroleptic malignant syndrome [49].

The most fraught decision in the management of DLB relates to the use of antipsychotic medications. In Alzheimer's disease and all-cause dementia studies, antipsychotic medications are rarely effective at reducing symptoms [50] and they increase the risk of stroke and sudden cardiac death by at least $50 \%$ [51, 52]. Ceasing these medications decreases the risk of death by the same amount [53]. The latter study counters the idea that the antipsychotic-associated mortality is due to confounding by indication. This theory states that end-stage dementia causes increased mortality and also causes the prescription of antipsychotics. Data from these pivotal studies led to a US Food and Drug Administration blackbox warning for antipsychotic medication use in dementia and a substantial change in prescribing practice.

A major factor in the success or otherwise of treatment trials of antipsychotic medications in DLB and other dementia relates to the target symptoms. Hallucinations and delusions are more likely to respond to these medications than behavioral disturbance, as described below. Physicians should reserve the use of neuroleptics for symptoms likely to respond to their use, after focused behavioral interventions have been attempted. There is ample evidence of efficacy for these behavioral interventions [54], but limited funds for implementation. Gitlin and colleagues provide an excellent description of such a program [55].

A continued role for antipsychotic treatment remains for the short-term treatment of subjects at risk of harm due to their psychosis [47]. Higher scores on the Neuropsychiatric Inventory may indicate a patient is more likely to respond to the treatment, particularly if the findings are within the domains most amenable to treatment with neuroleptic medication (see discussion below) [56].

DLB patients are particularly at risk of antipsychotic medication morbidity and mortality. Severe neuroleptic sensitivity occurs in 30 to $50 \%$ of patients [57]. Typical antipsychotics (for example, haloperidol) are best avoided [57], but reactions can occur after any neuroleptic and no differences in mortality were found between the atypical antipsychotics in all-dementia clinical trials [50]. Profound sedation, confusion, exacerbations of parkinsonism, rigidity, dysautonomia, and death can occur $[4,16,57,58]$ even after a single dose $[57,59,60]$. These effects are associated with a threefold increase in stroke occurrence and a twofold to fourfold increase in the rate of cognitive decline $[50,53]$. There is also evidence to the contrary, however. Antipsychotic medications have been well tolerated in DLB trials [61, 62], and a large observational study that controlled for cardiovascular risk and psychosis severity found no increase in mortality amongst Alzheimer's disease patients [63]. Irrespective of the controversy over the degree of risk, the large placebo response seen in trials of antipsychotics [27, 50] and the data showing improved survival for those taken off long-term antipsychotics treatment [53] dictate that all new prescriptions of antipsychotics should include a programmed trial of cessation [64].

The choice of which antipsychotic to use is also a vexed question. Quetiapine and clozapine are equally effective in head-to-head PDD trials $[49,65]$, although other data show mixed results for quetiapine in underpowered trials of DLB/PDD [20, 61, 62, 66, 67]. Despite the paucity of evidence for its efficacy, many clinicians use quetiapine, reserving clozapine for second-line or third-line treatment because of its potential to cause agranulocytosis [68-72]. More data are sorely needed to inform antipsychotic medication choice in DLB. In the interim, it is reasonable to select antipsychotic medications on the basis of their side-effect profiles. Patients at risk for diabetes or hyperlipidemia should avoid quetiapine, olanzapine and clozapine, whereas those with elevated cerebrovascular risk should avoid olanzapine and risperidone [47]. Olanzapine is also associated with motor decline in PD patients with psychosis [20]. The Movement Disorders Society advises against olanzapine use in PD [20], advice that might reasonably be extended to DLB patients. Irrespective of which antipsychotic medication is used, prescribers should be wary of the cardiac denervation seen in the synucleinopathies [22] and so consider monitoring the QT interval. This is especially important when cholinesterase inhibitor and neuroleptic medications are used together. Fortunately, several new agents without such side effects are under development. For example, a recent trial of pimavanserin, a 
selective serotonin 5-HT2A inverse agonist, shows great promise in the treatment of PDD, both in terms of treatment response and trial design [73].

\section{Agitation and behavioral disturbance}

Agitation and behavioral disturbance often respond to simple measures such as caregiver training, removal of fear triggers, and increased social interaction [74]. Many triggers for agitation are fleeting, and episodes of agitation are self-limiting, so watchful waiting is often preferable to antipsychotic prescription [53]. In the late stages of disease, when patients have difficulty expressing their needs, pain is often a trigger for agitation: investigation for potential sources of pain and empiric treatment with simple analgesics such as acetaminophen should be firstline therapy [75]. Antipsychotic medications have the same qualifications to their use as noted above. Furthermore, behavioral disturbances such as sleep-wake cycle disturbance, shouting, oppositional behavior, pacing, agitation, and aggression are not good targets of therapy for the neuroleptic medications. There are numerous carer training programs designed to decrease the disturbances, but only six medications have evidence for efficacy, three of which are readily accessible [76-78]. Successful programs train caregivers to understand care situations from the perspective of people with moderate to severe dementia, and to adapt their approach to such encounters to encourage respect for the patient's personhood [55]. Extensive training is required for program success [76-78].

\section{Movement symptoms}

The motor symptoms and signs of DLB are similar to those found in PD, including rigidity, bradykinesia, tremor, and gait difficulties. They may respond to physical therapy and home safety modification. As is the case in PD, the primary prevention of falls is paramount in DLB. Education on the importance of this point can be punctuated with advice such as gravity is your mortal enemy'. Repeated falls should trigger a rapid assessment and treatment of the cause(s).

The same medications that are used in PD for movement symptoms are used in DLB, but they are usually less effective than in PD [79]. Their use is often limited because of their tendency to exacerbate the neuropsychiatric features of DLB [79-81]. Levodopa/carbidopa is most useful in patients with prominent parkinsonism and few or no neuropsychiatric symptoms [81]. Levodopa/carbidopa is used in preference to the dopamine agonists because the latter are more likely to induce compulsive behavior. In one series, $24 \%$ of PD patients taking dopamine agonists suffered from this potentially devastating constellation of side effects [82]. Amantadine may reduce the severity of the compulsive behaviors, but can also worsen dysautonomia and hallucinations [20].
Physical therapy and home modification are effective in PD. Cholinesterase inhibitors may exacerbate tremor, but only mildly so, and do not otherwise worsen parkinsonism $[26,39]$. Where possible, medications that can induce parkinsonism should be avoided - these include the dopamine receptor blocking anti-emetics (for example, prochlorperazine and metoclopramide) and neuroleptics.

\section{Autonomic symptoms \\ Constipation}

The most common autonomic complications of synucleinopathy are under-recognized: $89 \%$ of PD patients have constipation or diarrhea. Sixteen percent of the patients have been hospitalized for bowel obstruction [24, 25]. Patients may be unaware that this is a consequence of their DLB, since the symptoms usually predate other aspects of the syndrome by many years [10, 21, 34]. Directed questions and early treatment with a high-fiber diet, exercise, stool softeners, psyllium [83], polyethylene glycol [84], methylcellulose, docusate, and misoprostol [49] are effective. Increased bowel activity is a common (and in this case welcome) side effect of cholinesterase inhibitor therapy.

\section{Genitourinary symptoms}

Up to $83 \%$ of PD patients experience urinary frequency, urgency, and incontinence [85], for which oral trospium and transdermal oxybutyinin are effective [20] alternatives to trihexyphenidyl and oral oxybutyinin, which cause confusion [8, 86-88]. Tamsulosin and bethanol chloride are effective for prostatism and urinary retention [49]. Sildenafil is effective for erectile dysfunction in PD [89], but prescription requests should trigger a review to determine whether levodopa or dopamine agonist treatment is inducing hypersexual behavior $[82,85]$.

\section{Postural hypotension}

Orthostatic symptoms are common in DLB [58, 90]; their frequency and severity is a strong predictor of prognosis [91]. Patients may not describe classic postural symptoms, but instead mention nonspecific weakness or lethargy. Reduction or cessation of antihypertensive medication, meal fragmentation, salt liberalization/supplementation and compression stockings [20], fludrocortisone [92], and domperidone [92] are all effective in the synucleinopathies. Cholinesterase inhibition [93] and pyrodostigmine [94] also improve these symptoms.

\section{Sleep symptoms}

\section{Excessive daytime sleepiness}

It is easy to underestimate the effect that excessive sleepiness can have on a patient's quality of life. Sedating medications should be ceased and obstructive sleep apnea, primary sleep disorders, and nocturia should be 
ruled out. Caffeine is a useful treatment in those without periodic leg movement disorder of sleep or restless leg syndrome [95]. The evidence for methylphenidate and dextroamphetamine is mixed [20]. Modafinil was effective in two of three PD trials [20,96]. Eighteen of 20 patients responded well in a small, unblinded trial of armodafinil [97].

\section{Rapid eye movement sleep behavior disorder}

Seventy-six percent of DLB patients act out their dreams [98]. When confirmed by polysomnography, rapid eye movement sleep behavior disorder is $98 \%$ specific to the disorders of synuclein [99]. The disorder may not require treatment unless it induces excessive daytime sleepiness, or poses a physical risk to the patient or their bed partner. Simple instructions can prevent harm: remove sharp objects from the bedside, use soft barriers around the bed, or sleep in a tightly closed sleeping bag (cocooning) $[95,100]$. The enacted dream often involves being chased or attacked, so bed partners should avoid the dreamer lest they be incorporated into the dream and attacked [95]. Randomized controlled trials demonstrate that melatonin [101-103], rivastigmine [104], and bed alarms that play soothing messages from caregivers [100] are effective rapid eye movement sleep behavior disorder treatments. The short half-life of melatonin means that a second dose may be needed if sleep is interrupted. Low-dose clonazepam is a recommended second-line therapy [105].

\section{Restless leg syndrome and periodic limb movement disorder}

These conditions often accompany the disorders of synuclein, and each other [106]. The treatment options are identical for the two disorders; however, periodic limb movement disorder does not require treatment unless it is disrupting sleep or sleep architecture. There are no trials of restless leg syndrome or periodic limb movement disorder treatment in the context of DLB. The dopamine agonists are not recommended in this setting for the reasons outlined earlier. Standard treatment of restless leg syndrome and limb movement disorder with carbidopa/levodopa, benzodiazepines (and especially clonazepam), and the alpha-2-delta calcium channel ligands (gabapentin, gabapentin enacarbil, and pregabalin) are effective in PD patients [106].

\section{Conclusions}

DLB is a complex disease with many challenging treatment decisions. It is often under-recognized in the clinic, in part because the core clinical diagnostic features - fluctuations in cognition, visual hallucinations, and parkinsonism - are nonspecific and subject to varied interpretation. For example, how much parkinsonism is enough to qualify for this feature? Treatment options can improve quality of life, but do not alter the course of the disease. For many symptoms, the best treatments are nondrug treatments. Regular reviews aimed at rationalizing therapy can be beneficial. For example, anti-hypertensive medications that were erstwhile well tolerated may induce postural dizziness because alpha-synucleinopathy weakens neurovascular tone. The most difficult decision relates to the use of antipsychotic medications; these occasionally benefit patients with hallucinations and delusions, but severe reactions such as prolonged rigidity and decreased responsiveness are common in DLB. Recent trials of antipsychotics with novel mechanisms of action hold promise for this vulnerable population.

Note: This article is part of a series on Lewy Body Dementia, edited by lan McKeith and James Galvin. Other articles in this series can be found at http://alzres.com/series/LewyBodyDementia

\section{Abbreviations}

DLB: dementia with Lewy bodies; PD: Parkinson's disease; PDD: Parkinson's disease dementia.

\section{Competing interests}

BPB receives funding from the Michael J Fox Foundation and the Parkinson's Disease Research Foundation, has served as an investigator for clinical trials sponsored by Pfizer, Janssen, Avid, and Bristol-Myers Squibb, and is an employee of Biogen Idec.

Published online: 29 May 2015

\section{References}

1. Nelson PT, Jicha GA, Kryscio RJ, Abner EL, Schmitt FA, Cooper G, et al. Low sensitivity in clinical diagnoses of dementia with Lewy bodies. J Neurol. 2010;257:359-66.

2. Vann Jones SA, O'Brien JT. The prevalence and incidence of dementia with Lewy bodies: a systematic review of population and clinical studies. Psychol Med. 2013:44:673-83.

3. Boot B. The incidence and prevalence of dementia with Lewy bodies is underestimated. Psychol Med. 2013;43:2687-8.

4. McKeith IG, Dickson DW, Lowe J, Emre M, O'Brien JT, Feldman H, et al. Diagnosis and management of dementia with Lewy bodies: third report of the DLB Consortium. Neurology. 2005;65:1863-72.

5. Ballard C, Aarsland D, Francis P, Corbett A. Neuropsychiatric symptoms in patients with dementias associated with cortical Lewy bodies: pathophysiology, clinical features, and pharmacological management. Drugs Aging. 2013;30:603-11.

6. Aarsland D, Zaccai J, Brayne C. A systematic review of prevalence studies of dementia in Parkinson's disease. Mov Disord. 2005;20:1255-63.

7. Schneider JA, Arvanitakis Z, Bang W, Bennett DA. Mixed brain pathologies account for most dementia cases in community-dwelling older persons. Neurology. 2007;69:2197-204

8. Ballard C, Holmes C, McKeith I, Neill D, O'Brien J, Cairns N, et al. Psychiatric morbidity in dementia with Lewy bodies: a prospective clinical and neuropathological comparative study with Alzheimer's disease. Am J Psychiatry. 1999;156:1039-45.

9. Ballard C, O'Brien J, Gray A, Cormack F, Ayre G, Rowan E, et al. Attention and fluctuating attention in patients with dementia with Lewy bodies and Alzheimer disease. Arch Neurol. 2001;58:977-82.

10. Boot BP, Orr CF, Ahlskog JE, Ferman TJ, Roberts R, Pankratz VS, et al. Risk factors for dementia with Lewy bodies: a case-control study. Neurology. 2013;81:833-40. 
11. Stubendorff $K$, Hansson O, Minthon L, Londos E. Differences in survival between patients with dementia with Lewy bodies and patients with Alzheimer's disease - measured from a fixed cognitive level. Dement Geriatr Cogn Disord. 2011;32:408-16.

12. Aarsland D, Mosimann UP, McKeith IG. Role of cholinesterase inhibitors in Parkinson's disease and dementia with Lewy bodies. J Geriatr Psychiatry Neurol. 2004;17:164-71.

13. Emre M, Aarsland D, Albanese A, Byrne E, Deuschl G, De Deyn P, et al. Rivastigmine for dementia associated with Parkinson's disease. N Engl J Med. 2004;351:2509-18.

14. Rolinski M, Fox C, Maidment I, McShane R. Cholinesterase inhibitors for dementia with Lewy bodies, Parkinson's disease dementia and cognitive impairment in Parkinson's disease. Cochrane Database Syst Rev. 2012;3:CD006504.

15. Emre M, Cummings $J$, Lane RM. Rivastigmine in dementia associated with Parkinson's disease and Alzheimer's disease: similarities and differences. J Alzheimers Dis. 2007;11:509-19.

16. Klein JC, Eggers C, Kalbe E, Weisenbach S, Hohmann C, Vollmar S, et al. Neurotransmitter changes in dementia with Lewy bodies and Parkinson disease dementia in vivo. Neurology. 2010;74:885-92.

17. Ferman TJ, Smith GE, Boeve BF, Ivnik RJ, Petersen RC, Knopman D, et al. DLB fluctuations: specific features that reliably differentiate DLB from $A D$ and normal aging. Neurology. 2004;62:181-7.

18. Mori E, Ikeda M, Kosaka K. Donepezil for dementia with Lewy bodies: a randomized, placebo-controlled trial. Ann Neurol. 2012;72:41-52.

19. Ikeda M, Mori E, Kosaka K, Iseki E, Hashimoto M, Matsukawa N, et al. Longterm safety and efficacy of donepezil in patients with dementia with Lewy bodies: results from a 52-week, open-label, multicenter extension study. Dement Geriatr Cogn Disord. 2013;36:229-41.

20. Seppi K, Weintraub D, Coelho M, Perez-Lloret S, Fox SH, Katzenschlager R, et al. The Movement Disorder Society evidence-based medicine review update: treatments for the non-motor symptoms of Parkinson's disease. Mov Disord. 2011;26:S42-80.

21. Postuma RB, Gagnon JF, Pelletier A, Montplaisir J. Prodromal autonomic symptoms and signs in Parkinson's disease and dementia with Lewy bodies. Mov Disord. 2013;28:597-604.

22. Treglia G, Cason E, Stefanelli A, Cocciolillo F, Di Giuda D, Fagioli G, et al. MIBG scintigraphy in differential diagnosis of Parkinsonism: a meta-analysis. Clin Auton Res. 2012;22:43-55.

23. Rosenbloom MH, Finley R, Scheinman MM, Feldman MD, Miller BL, Rabinovici GD. Donepezil-associated bradyarrhythmia in a patient with dementia with Lewy bodies (DLB). Alzheimer Dis Assoc Disord. 2010;24:209-11.

24. Lawrence J, Parmenter T, McDonald T. Failure to manage constipation in Parkinson's disease. A review of medical services: a patients perspective. Movement Disorders. 2013;28 Suppl 1:187.

25. Jost WH. Gastrointestinal motility problems in patients with Parkinson's disease. Effects of antiparkinsonian treatment and guidelines for management. Drugs Aging. 1997;10:249-58.

26. Wesnes KA, McKeith I, Edgar C, Emre M, Lane R. Benefits of rivastigmine on attention in dementia associated with Parkinson disease. Neurology. 2005;65:1654-6.

27. Aarsland D, Ballard C, Rongve A, Broadstock M, Svenningsson P. Clinical trials of dementia with Lewy bodies and Parkinson's disease dementia. Curr Neurol Neurosci Rep. 2012;12:492-501.

28. Emre M, Tsolaki M, Bonuccelli U, Destee A, Tolosa E, Kutzelnigg A, et al. Memantine for patients with Parkinson's disease dementia or dementia with Lewy bodies: a randomised, double-blind, placebo-controlled trial. Lancet Neurol. 2010;9:969-77.

29. Weintraub D, Mavandadi S, Mamikonyan E, Siderowf AD, Duda JE, Hurtig HI, et al. Atomoxetine for depression and other neuropsychiatric symptoms in Parkinson disease. Neurology. 2010;75:448-55.

30. Hanagasi HA, Gurvit H, Unsalan P, Horozoglu H, Tuncer N, Feyzioglu A, et al. The effects of rasagiline on cognitive deficits in Parkinson's disease patients without dementia: a randomized, double-blind, placebo-controlled, multicenter study. Mov Disord. 2011;26:1851-8.

31. Kehagia AA, Barker RA, Robbins TW. Neuropsychological and clinical heterogeneity of cognitive impairment and dementia in patients with Parkinson's disease. Lancet Neurol. 2010;9:1200-13.

32. Cooper JA, Sagar HJ, Doherty SM, Jordan N, Tidswell P, Sullivan EV. Different effects of dopaminergic and anticholinergic therapies on cognitive and motor function in Parkinson's disease. A follow-up study of untreated patients. Brain. 1992;115 Pt 6:1701-25.
33. Svenningsson P, Westman E, Ballard C, Aarsland D. Cognitive impairment in patients with Parkinson's disease: diagnosis, biomarkers, and treatment. Lancet Neurol. 2012;11:697-707.

34. Savica R, Rocca WA, Ahlskog JE. When does Parkinson disease start? Arch Neurol. 2010;67:798-801.

35. Ohara K, Kondo N, Ohara K. Changes of monoamines in post-mortem brains from patients with diffuse Lewy body disease. Prog Neuropsychopharmacol Biol Psychiatry. 1998:22:311-7.

36. Sharp SI, Ballard CG, Ziabreva I, Piggott MA, Perry RH, Perry EK, et al. Cortical serotonin $1 \mathrm{~A}$ receptor levels are associated with depression in patients with dementia with Lewy bodies and Parkinson's disease dementia. Dement Geriatr Cogn Disord. 2008;26:330-8.

37. Postuma RB, Lang AE, Gagnon JF, Pelletier A, Montplaisir JY. How does parkinsonism start? Prodromal parkinsonism motor changes in idiopathic REM sleep behaviour disorder. Brain. 2012;135:1860-70.

38. Lerche S, Hobert M, Brockmann K, Wurster I, Gaenslen A, Hasmann S, et al. Mild parkinsonian signs in the elderly - is there an association with PD? Crossectional findings in 992 individuals. PLoS One. 2014;9:e92878.

39. McKeith IG, Ballard CG, Perry RH, Ince PG, O'Brien JT, Neill D, et al. Prospective validation of consensus criteria for the diagnosis of dementia with Lewy bodies. Neurology. 2000:54:1050-8.

40. Cummings JL, Street J, Masterman D, Clark WS. Efficacy of olanzapine in the treatment of psychosis in dementia with lewy bodies. Dement Geriatr Cogn Disord. 2002;13:67-73.

41. Culo S, Mulsant BH, Rosen J, Mazumdar S, Blakesley RE, Houck PR, et al. Treating neuropsychiatric symptoms in dementia with Lewy bodies: a randomized controlled-trial. Alzheimer Dis Assoc Disord. 2010;24:360-4

42. Weintraub D, Morales KH, Moberg PJ, Bilker WB, Balderston C, Duda JE, et al. Antidepressant studies in Parkinson's disease: a review and meta-analysis. Mov Disord. 2005;20:1161-9.

43. Chung TH, Deane KH, Ghazi-Noori S, Rickards H, Clarke CE. Systematic review of antidepressant therapies in Parkinson's disease. Parkinsonism Relat Disord. 2003;10:59-65.

44. Takahashi S, Mizukami K, Yasuno F, Asada T. Depression associated with dementia with Lewy bodies (DLB) and the effect of somatotherapy. Psychogeriatrics. 2009;9:56-61.

45. Truong DD, Bhidayasiri R, Wolters E. Management of non-motor symptoms in advanced Parkinson disease. J Neurol Sci. 2008;266:216-28.

46. Ferman TJ, Boeve BF, Smith GE, Graff-Radford NR. The phenomenology of psychotic features in dementia with Lewy bodies (DLB) and Alheimer's diesease (AD). Neurology. 2005;64:A257.

47. Gauthier S, Cummings J, Ballard C, Brodaty H, Grossberg G, Robert P, et al. Management of behavioral problems in Alzheimer's disease. Int Psychogeriatr. 2010;22:346-72.

48. Uchiyama M, Nishio Y, Yokoi K, Hirayama K, Imamura T, Shimomura T, et al. Pareidolias: complex visual illusions in dementia with Lewy bodies. Brain. 2012;135:2458-69.

49. Wood LD, Neumiller JJ, Setter SM, Dobbins EK. Clinical review of treatment options for select nonmotor symptoms of Parkinson's disease. Am J Geriatr Pharmacother. 2010;8:294-315.

50. Schneider LS, Dagerman K, Insel PS. Efficacy and adverse effects of atypical antipsychotics for dementia: meta-analysis of randomized, placebocontrolled trials. Am J Geriatr Psychiatry. 2006;14:191-210.

51. Ballard C, Powell I, James I, Reichelt K, Myint P, Potkins D, et al. Can psychiatric liaison reduce neuroleptic use and reduce health service utilization for dementia patients residing in care facilities. Int J Geriatr Psychiatry. 2002;17:140-5.

52. Musicco M, Palmer K, Russo A, Caltagirone C, Adorni F, Pettenati C, et al. Association between prescription of conventional or atypical antipsychotic drugs and mortality in older persons with Alzheimer's disease. Dement Geriatr Cogn Disord. 2011;31:218-24.

53. Ballard C, Hanney ML, Theodoulou M, Douglas S, McShane R, Kossakowski K, et al. The dementia antipsychotic withdrawal trial (DART-AD): long-term follow-up of a randomised placebo-controlled trial. Lancet Neurol. 2009;8:151-7.

54. Brodaty $\mathrm{H}$, Arasaratnam C. Meta-analysis of nonpharmacological interventions for neuropsychiatric symptoms of dementia. Am J Psychiatry. 2012;169:946-53.

55. Gitlin LN, Kales HC, Lyketsos CG. Nonpharmacologic management of behavioral symptoms in dementia. JAMA. 2012;308:2020-9.

56. Ballard CG, Thomas A, Fossey J, Lee L, Jacoby R, Lana MM, et al. A 3-month, randomized, placebo-controlled, neuroleptic discontinuation study in 100 people with dementia: the neuropsychiatric inventory median cutoff is a predictor of clinical outcome. J Clin Psychiatry. 2004;65:114-9. 
57. Aarsland D, Perry R, Larsen JP, McKeith IG, O'Brien JT, Perry EK, et al. Neuroleptic sensitivity in Parkinson's disease and parkinsonian dementias. J Clin Psychiatry. 2005;66:633-7.

58. Ballard C, Howard R. Neuroleptic drugs in dementia: benefits and harm. Nat Rev Neurosci. 2006;7:492-500.

59. Rochon PA, Stukel TA, Sykora K, Gill S, Garfinkel S, Anderson GM, et al. Atypical antipsychotics and parkinsonism. Arch Intern Med. 2005;165:1882-8.

60. Hassan I. Consultation-liaison psychiatry and prevention of severe neuroleptic sensitivity reactions in dementia with Lewy bodies. Australas Psychiatry. 2011:19:536-7.

61. Fernandez HH, Trieschmann ME, Burke MA, Friedman JH. Quetiapine for psychosis in Parkinson's disease versus dementia with Lewy bodies. J Clin Psychiatry. 2002;63:513-5.

62. Kurlan R, Cummings J, Raman R, Thal L, Alzheimer's Disease Cooperative Study G. Quetiapine for agitation or psychosis in patients with dementia and parkinsonism. Neurology. 2007;68:1356-63.

63. Lopez O, Becker J, Chang Y, Sweet R, Aizenstein H, Snitz B, et al. The longterm effects of conventional and atypical antipsychotics in patients with probable Alzheimer's disease. Am J Psychiatry. 2013;170:1051-8.

64. Boot BP, McDade EM, McGinnis SM, Boeve BF. Treatment of dementia with lewy bodies. Curr Treat Options Neurol. 2013;15:738-64.

65. Frieling $H$, Hillemacher $T$, Ziegenbein M, Neundorfer B, Bleich S. Treating dopamimetic psychosis in Parkinson's disease: structured review and meta-analysis. Eur Neuropsychopharmacol. 2007;17:165-71.

66. Schneider L, Tariot P, Dagerman K, Davis S, Hsiao J, Ismail M, et al. Effectiveness of atypical antipsychotic drugs in patients with Alzheimer's disease. N Engl J Med. 2006;355:1525-38.

67. Fernandez HH, Trieschmann ME, Burke MA, Jacques C, Friedman JH. Longterm outcome of quetiapine use for psychosis among Parkinsonian patients. Mov Disord. 2003;18:510-4.

68. Factor SA, Friedman JH, Lannon MC, Oakes D, Bourgeois K. Clozapine for the treatment of drug-induced psychosis in Parkinson's disease: results of the 12 week open label extension in the PSYCLOPS trial. Mov Disord. 2001;16:135-9.

69. Pollak P, Tison F, Rascol O, Destee A, Pere JJ, Senard JM, et al. Clozapine in drug induced psychosis in Parkinson's disease: a randomised, placebo controlled study with open follow up. J Neurol Neurosurg Psychiatry. 2004;75:689-95.

70. Morgante L, Epifanio A, Spina E, Zappia M, Di Rosa AE, Marconi R, et al. Quetiapine and clozapine in parkinsonian patients with dopaminergic psychosis. Clin Neuropharmacol. 2004;27:153-6.

71. Merims D, Balas M, Peretz C, Shabtai H, Giladi N. Rater-blinded, prospective comparison: quetiapine versus clozapine for Parkinson's disease psychosis. Clin Neuropharmacol. 2006;29:331-7.

72. Fox SH, Katzenschlager R, Lim SY, Ravina B, Seppi K, Coelho M, et al. The Movement Disorder Society evidence-based medicine review update: treatments for the motor symptoms of Parkinson's disease. Mov Disord. 2011;26:S2-41.

73. Cummings J, Isaacson S, Mills R, Williams H, Chi-Burris K, Corbett A, et al. Pimavanserin for patients with Parkinson's disease psychosis: a randomised, placebo-controlled phase 3 trial. Lancet. 2014;383:533-40.

74. Rhodes-Kropf J, Cheng H, Castillo EH, Fulton AT. Managing the patient with dementia in long-term care. Clin Geriatr Med. 2011;27:135-52.

75. Husebo BS, Ballard C, Sandvik R, Nilsen OB, Aarsland D. Efficacy of treating pain to reduce behavioural disturbances in residents of nursing homes with dementia: cluster randomised clinical trial. BMJ. 2011;343:d4065.

76. Fossey J, Ballard C, Juszczak E, James I, Alder N, Jacoby R, et al. Effect of enhanced psychosocial care on antipsychotic use in nursing home residents with severe dementia: cluster randomised trial. BMJ. 2006:332:756-61.

77. Chenoweth L, King MT, Jeon YH, Brodaty H, Stein-Parbury J, Norman R, et al. Caring for Aged Dementia Care Resident Study (CADRES) of person-centred care, dementia-care mapping, and usual care in dementia: a clusterrandomised trial. Lancet Neurol. 2009;8:317-25.

78. Brooker DJ, Argyle E, Scally AJ, Clancy D. The enriched opportunities programme for people with dementia: a cluster-randomised controlled trial in 10 extra care housing schemes. Aging Mental Health. 2011;15:1008-17.

79. Lucetti C, Logi C, Del Dotto P, Berti C, Ceravolo R, Baldacci F, et al. Levodopa response in dementia with lewy bodies: a 1-year follow-up study. Parkinsonism Relat Disord. 2010;16:522-6.

80. Molloy S, McKeith IG, O'Brien JT, Burn DJ. The role of levodopa in the management of dementia with Lewy bodies. J Neurol Neurosurg Psychiatry. 2005;76:1200-3.
81. Goldman JG, Goetz CG, Brandabur M, Sanfilippo M, Stebbins GT. Effects of dopaminergic medications on psychosis and motor function in dementia with Lewy bodies. Mov Disord. 2008;23:2248-50.

82. Hassan A, Bower JH, Kumar N, Matsumoto JY, Fealey RD, Josephs KA, et al. Dopamine agonist-triggered pathological behaviors: surveillance in the PD clinic reveals high frequencies. Parkinsonism Relat Disord. 2011;17:260-4.

83. Ashraf W, Pfeiffer RF, Park F, Lof J, Quigley EM. Constipation in Parkinson's disease: objective assessment and response to psyllium. Mov Disord. 1997;12:946-51.

84. Zangaglia R, Martignoni E, Glorioso M, Ossola M, Riboldazzi G, Calandrella D, et al. Macrogol for the treatment of constipation in Parkinson's disease. A randomized placebo-controlled study. Mov Disord. 2007;22:1239-44.

85. Ziemssen T, Reichmann H. Non-motor dysfunction in Parkinson's disease. Parkinsonism Relat Disord. 2007;13:323-32.

86. Kay GG, Abou-Donia MB, Messer Jr WS, Murphy DG, Tsao JW, Ouslander JG Antimuscarinic drugs for overactive bladder and their potential effects on cognitive function in older patients. J Am Geriatr Soc. 2005;53:2195-201.

87. Pagoria D, O'Connor RC, Guralnick ML. Antimuscarinic drugs: review of the cognitive impact when used to treat overactive bladder in elderly patients. Curr Urol Rep. 2011;12:351-7.

88. Todorova A, Vonderheid-Guth B, Dimpfel W. Effects of tolterodine, trospium chloride, and oxybutynin on the central nervous system. J Clin Pharmacol. 2001;41:636-44.

89. Hussain IF, Brady CM, Swinn MJ, Mathias CJ, Fowler CJ. Treatment of erectile dysfunction with sildenafil citrate (Viagra) in parkinsonism due to Parkinson's disease or multiple system atrophy with observations on orthostatic hypotension. J Neurol Neurosurg Psychiatry. 2001;71:371-4.

90. Thaisetthawatkul P, Boeve B, Benarroch E, Sandroni P, Ferman T, Petersen R, et al. Autonomic dysfunction in dementia with Lewy bodies. Neurology. 2004;62:1804-9.

91. Stubendorff K, Aarsland D, Minthon L, Londos E. The impact of autonomic dysfunction on survival in patients with dementia with Lewy bodies and Parkinson's disease with dementia. PLoS One. 2012;7:e45451.

92. Schoffer KL, Henderson RD, O'Maley K, O'Sullivan JD. Nonpharmacological treatment, fludrocortisone, and domperidone for orthostatic hypotension in Parkinson's disease. Mov Disord. 2007;22:1543-9.

93. Singer W, Opfer-Gehrking TL, McPhee BR, Hilz MJ, Bharucha AE, Low PA. Acetylcholinesterase inhibition: a novel approach in the treatment of neurogenic orthostatic hypotension. J Neurol Neurosurg Psychiatry. 2003;74:1294-8.

94. Singer W, Sandroni P, Opfer-Gehrking TL, Suarez GA, Klein CM, Hines S, et al. Pyridostigmine treatment trial in neurogenic orthostatic hypotension. Arch Neurol. 2006;63:513-8.

95. Malhotra R, Avidan AY. Neurodegenerative disease and REM behavior disorder. Curr Treat Options Neurol. 2012;14:474-92.

96. Hogl B, Saletu M, Brandauer E, Glatzl S, Frauscher B, Seppi K, et al. Modafinil for the treatment of daytime sleepiness in Parkinson's disease: a doubleblind, randomized, crossover, placebo-controlled polygraphic trial. Sleep. 2002;25:905-9.

97. Kuntz K, Boeve B, Drubach D, Allen L, Drubach D. Safety, tolerability, and efficacy of armodafinil therapy for hypersomnia associated with dementia with Lewy bodies. Neurology. 2012;78:P04.192.

98. Ferman TJ, Boeve BF, Smith GE, Lin SC, Silber MH, Pedraza O, et al. Inclusion of RBD improves the diagnostic classification of dementia with Lewy bodies. Neurology. 2011;77:875-82.

99. Boeve BF, Silber MH, Ferman TJ, Lin SC, Benarroch EE, Schmeichel AM, et al. Clinicopathologic correlations in 172 cases of rapid eye movement sleep behavior disorder with or without a coexisting neurologic disorder. Sleep Med. 2013;14:754-62.

100. Howell MJ, Arneson PA, Schenck CH. A novel therapy for REM sleep behavior disorder (RBD). J Clin Sleep Med. 2011;7:639-44A.

101. Boeve B, Silber M, Ferman T. Melatonin for treatment of REM sleep behavior disorder in neurologic disorders: results in 14 patients. Sleep Med. 2003:4:281-4.

102. Dowling GA, Mastick J, Colling E, Carter JH, Singer CM, Aminoff MJ. Melatonin for sleep disturbances in Parkinson's disease. Sleep Med. 2005;6:459-66.

103. Medeiros CA, De Bruin Carvalhedo PF, Lopes LA, Magalhaes MC, de Lourdes Seabra M, de Bruin VM. Effect of exogenous melatonin on sleep and motor dysfunction in Parkinson's disease. A randomized, double blind, placebocontrolled study. J Neurol. 2007;254:459-64.

104. Di Giacopo R, Fasano A, Quaranta D, Della Marca G, Bove F, Bentivoglio AR. Rivastigmine as alternative treatment for refractory REM behavior disorder in Parkinson's disease. Mov Disord. 2012;27:559-61. 
105. Aurora RN, Zak RS, Maganti RK, Auerbach SH, Casey KR, Chowdhuri S, et al. Best practice guide for the treatment of REM sleep behavior disorder (RBD). J Clin Sleep Med. 2010;6:85-95

106. Hening WA, Allen RP, Earley CJ, Picchietti DL, Silber MH. Restless Legs Syndrome Task Force of the Standards of Practice Committee of the American Academy of Sleep Medicine. An update on the dopaminergic treatment of restless legs syndrome and periodic limb movement disorder. Sleep. 2004;27:560-83. 